\title{
Relationships between dry matter content, ensiling, ammonia-nitrogen, and ruminal in vitro starch digestibility in high-moisture corn samples
}

\author{
L. F. Ferraretto, ${ }^{\star}$ K. Taysom, $†$ D. M. Taysom, $\dagger$ R. D. Shaver, ${ }^{\star 1}$ and P. C. Hoffman* \\ ${ }^{*}$ Department of Dairy Science, University of Wisconsin-Madison, Madison 53706 \\ †Dairyland Laboratories Inc., Arcadia, WI 54612
}

\begin{abstract}
The objectives of the study were (1) to determine relationships between high-moisture corn (HMC) dry matter (DM), ammonia-N [\% of crude protein (CP)], and soluble $\mathrm{CP}$ concentrations, and $\mathrm{pH}$, with 7-h ruminal in vitro starch digestibility (ivStarchD), and (2) to evaluate the effect of ensiling on $\mathrm{pH}$, ammonia- $\mathrm{N}$, soluble CP, and ivStarchD measurements in HMC. A data set comprising 6,131 HMC samples (55 to $80 \%$ DM) obtained from a commercial feed analysis laboratory was used for this study. Month of sample submittal was assumed to be associated with length of the ensiling period. Data for month of sample submittal were analyzed using Proc Mixed in SAS (SAS Institute Inc., Cary, NC) with month as a fixed effect. Regressions to determine linear and quadratic relationships between ivStarchD and ammonia-N, soluble $\mathrm{CP}, \mathrm{pH}$, and DM content were performed using Proc Mixed. The ivStarchD increased by 9 percentage units from October to August of the following year. Similar results were observed for ammonia- $\mathrm{N}$ and soluble $\mathrm{CP}$ with increases from 1.8 to $4.6 \%$ of $\mathrm{CP}$ and 31.3 to $46.4 \%$ of CP, respectively, from October to August of the following year. Ammonia- $\mathrm{N}$ was positively related to ivStarchD $\left(\mathrm{R}^{2}=0.61\right)$. The DM content of HMC at silo removal was negatively related $\left(\mathrm{R}^{2}=0.47\right)$ to ivStarchD with a decrease of 1.6 percentage units in ivStarchD per 1-percentage-unit increase in $\mathrm{DM}$ content. The $\mathrm{pH}$ of HMC was negatively related to ammonia- $\mathrm{N}\left(\mathrm{R}^{2}=\right.$ $0.53)$, soluble $\mathrm{CP}\left(\mathrm{R}^{2}=0.57\right)$, and ivStarchD $\left(\mathrm{R}^{2}=\right.$ 0.51). Combined, ammonia- $\mathrm{N}, \mathrm{DM}$, soluble $\mathrm{CP}$, and $\mathrm{pH}$ provided a good prediction of ivStarchD (adjusted $\mathrm{R}^{2}$ $=0.70)$. Increasing $\mathrm{pH}$, ammonia- $\mathrm{N}$, soluble $\mathrm{CP}$, and ivStarchD values indicate that HMC may need up to 10 mo of ensiling to reach maximum starch digestibility. Ammonia-N, DM content, soluble CP concentration, and $\mathrm{pH}$ are good indicators of ruminal in vitro starch digestibility for high-moisture corn.
\end{abstract}

Received November 4, 2013.

Accepted January 7, 2014.

${ }^{1}$ Corresponding author: rdshaver@wisc.edu
Key words: high-moisture corn, ammonia-N, starch digestibility

\section{INTRODUCTION}

Greater ruminal and total-tract starch digestibility is well established in dairy cows fed high-moisture corn (HMC) compared with dry corn (Firkins et al., 2001; Ferraretto et al., 2013). This is related to breakdown of the hydrophobic starch-protein matrix surrounding starch granules during ensiling (Kotarski et al., 1992; Philippeau and Michalet-Doreau, 1998), which allows for greater microbial fermentation and enzymatic digestion of starch by ruminants (McAllister et al., 1993; Huntington, 1997). Starch digestibility of HMC, however, may be altered by several factors, including mean particle size (MPS; Ekinci and Broderick, 1997; Ferraretto et al., 2013), harvest maturity and moisture content (Correa et al., 2002; Ngonyamo-Majee et al., 2009), and endosperm type (Philippeau et al., 1999; Lopes et al., 2009).

Hoffman et al. (2011) reported that ensiling HMC for $240 \mathrm{~d}$ reduced the zein-protein subunits that cross-link starch granules and suggested that the starch-protein matrix was degraded by proteolytic activity over an extended ensiling period. This could explain reports of greater ruminal in situ DM degradability for HMC with lower DM contents and longer duration of silage fermentation (Benton et al., 2005). Ammonia-N content increased, however, as HPLC zein-protein subunits in HMC decreased (Hoffman et al., 2011), and ammonia$\mathrm{N}$ has been suggested in combination with MPS for modeling the effects of corn maturity, DM content, and length of silage fermentation time on ruminal and total-tract starch digestibilities and rate of ruminal starch degradation for $\mathrm{HMC}$ at feed-out (Hoffman et al., 2012). A better understanding of the effects of extended ensiling period on starch digestibility would allow dairy farmers and nutritionists to optimize diets to circumvent decreased milk and protein yields with low starch digestibility or increased subacute rumen acidosis and milk fat depression with high starch digestibility (Krause and Oetzel, 2006; Ferraretto et al., 2013). 
Although controlled experiments on the aforementioned factors and relationships are available in the literature, attempts to further evaluate using commercial laboratory data were not found. Therefore, experimental objectives were (1) to determine relationships of HMC DM, ammonia-N, and soluble CP concentrations, and $\mathrm{pH}$ with $7 \mathrm{~h}$ ruminal in vitro starch digestibility (ivStarchD), and (2) to evaluate the effect of ensiling on HMC pH, ammonia-N, soluble $\mathrm{CP}$, and ivStarchD measurements.

\section{MATERIALS AND METHODS}

A data set comprising 6,131 HMC samples (55 to $80 \%$ DM) was obtained from Dairyland Laboratories Inc. (Arcadia, WI). All samples had previously been analyzed for DM, ammonia-N, and soluble CP concentrations and ivStarchD at Dairyland Laboratories Inc. The reported date of submittal for each sample was included in the data set and ranged from March 2011 to May 2013. Ammonia-N and soluble CP were reported as a percentage of CP. Samples were analyzed either by near-infrared spectroscopy (NIRS) prediction equations (using a Foss model 5000; Foss-NIR System, Silver Spring, MD) or wet chemistry procedures as follows: DM (method 930.15, AOAC International, 2000), ash (method 942.05, AOAC International, 2000), CP (method 990.03, AOAC International, 2000), crude fat (method 920.39, AOAC International, 2000), ADF (method 973.18, AOAC International, 2000), NDF (method 2002.04, AOAC International, 2006), starch (Bach Knudsen, 1997; YSI Biochemistry Analyzer, YSI Inc., Yellow Springs, OH), borate-phosphate buffersoluble CP (Krishnamoorthy et al., 1982), ammonia-N (method 973.49, AOAC International, 2000), and ruminal in vitro starch digestibility at $7 \mathrm{~h}$ (Richards et al., 1995). Descriptive statistics for variables included in the analysis and selected nutrient composition of the samples are given in Table 1. Month of sample submittal was assumed to be associated with length of the ensiling period. Possible effects of MPS could not be considered in this study, because ivStarchD was measured on samples of a defined 4-mm grind size.

Data evaluating the effects of month of submittal were analyzed using Proc Mixed of SAS (SAS Institute, 2004) with month as a fixed effect. To evaluate possible confounding by date and year, a secondary analysis was performed using data ranging from October 2011 to September 2012. The pattern of results for this analysis was similar to the pattern observed for the whole data set and therefore not presented. Regressions to determine linear and quadratic relationships between ivStarchD, ammonia-N, soluble $\mathrm{CP}, \mathrm{pH}$, and $\mathrm{DM}$ content were performed using Proc Reg of SAS (SAS Insti- tute, 2004). Best-fit regression (linear or quadratic) was chosen using the highest coefficient of determination $\left(\mathrm{R}^{2}\right)$ and lowest root mean square error (RMSE) as indicators. A backward elimination of multiple regressions was conducted to generate a predictive equation for ivStarchD using Proc Reg of SAS (SAS Institute, 2004). Best-fit regression was chosen based on the highest adjusted coefficient of determination (adjusted $\mathrm{R}^{2}$ ) and lowest RMSE as indicators. Statistical significance and trends were declared at $P \leq 0.05$ and $P>0.05$ to $P<0.10$, respectively.

\section{RESULTS AND DISCUSSION}

Fermentation profile and ivStarchD results for HMC by month of sample submittal are in Table 2. Month of sample submittal was used as an indicator of length of the ensiling period in the survey. The $\mathrm{pH}$ of HMC gradually decreased $(P=0.001)$ from 4.68 in October to 4.40 in April of the following year. A decrease in $\mathrm{pH}$ was reported by Baron et al. (1986) and Wardynski et al. (1993) when HMC was ensiled for up to 90 or $165 \mathrm{~d}$, respectively, and was thought to be related to increased concentrations of acetate and lactate over time. Likewise, a gradual decrease in $\mathrm{pH}$ was reported from 120 to 365 d of storage (Stock et al., 1991). Decreased pH over extended periods of storage is in agreement with bacterial activity in HMC when the fermentation process was evaluated for up to 200 d (Burmeister et al., 1966; Bothast et al., 1975). However, $\mathrm{pH}$ was slightly higher in May and June than in April, which may be related to either aerobic instability as temperature increases during the summer months or lack of inoculation for some of the samples, which can reduce aerobic stability at feed-out (Taylor and Kung, 2002; Kung et al., 2007). Although differences $(P=0.001)$ in sample DM content over time were observed, they did not fol-

Table 1. Descriptive statistics for high-moisture corn nutrient composition and $\mathrm{pH}$

\begin{tabular}{lccc}
\hline Item & $\mathrm{n}^{1}$ & Average & $\mathrm{SD}$ \\
\hline DM, \% as fed & 6,131 & 72.7 & 4.1 \\
CP, \% of DM & 6,119 & 8.1 & 1.7 \\
Soluble CP, \% of CP & 6,131 & 37.3 & 13.3 \\
Ammonia-N, \% of CP & 6,131 & 2.9 & 2.4 \\
NDF, \% of DM & 5,984 & 7.1 & 1.4 \\
ADF, \% of DM & 5,915 & 2.6 & 0.7 \\
Starch, \% of diet DM & 6,104 & 69.2 & 2.2 \\
ivStarchD, \% of starch & 6,131 & 60.9 & 9.5 \\
Fat, \% of DM & 4,985 & 3.4 & 0.4 \\
Ash, \% of DM & 4,985 & 1.4 & 0.1 \\
pH & 5,927 & 4.52 & 0.33 \\
\hline
\end{tabular}

${ }^{1}$ Number of samples.

${ }^{2}$ Ruminal in vitro starch digestibility at $7 \mathrm{~h}$. 
Table 2. Effect of month of sample submittal on high-moisture corn fermentation profile and ruminal in vitro starch digestibility

\begin{tabular}{|c|c|c|c|c|c|c|}
\hline Month $^{1}$ & $\mathrm{n}^{2}$ & $\mathrm{pH}$ & $\begin{array}{c}\text { DM, } \\
\% \text { as fed }\end{array}$ & $\begin{array}{l}\text { Soluble CP, } \\
\text { \% of CP }\end{array}$ & $\underset{\% \text { of } \mathrm{CP}}{\text { Ammonia-N }}$ & $\begin{array}{l}\text { ivStarchD, }{ }^{3} \\
\% \text { of starch }\end{array}$ \\
\hline October & 903 & $4.68^{\mathrm{a}}$ & $73.0^{\mathrm{b}}$ & $31.3^{\mathrm{f}}$ & $1.8^{\mathrm{g}}$ & $56.6^{\mathrm{g}}$ \\
\hline November & 649 & $4.65^{\mathrm{ab}}$ & $73.5^{\mathrm{a}}$ & $32.4^{\mathrm{f}}$ & $2.0^{\mathrm{f}}$ & $58.7^{\mathrm{f}}$ \\
\hline January & 775 & $4.43^{\mathrm{ef}}$ & $72.4^{\text {cde }}$ & $38.0^{\mathrm{c}}$ & $2.8^{\mathrm{e}}$ & $60.6^{\mathrm{e}}$ \\
\hline February & 438 & $4.43^{\mathrm{ef}}$ & $73.0^{\mathrm{b}}$ & $35.3^{\mathrm{e}}$ & $2.8^{\mathrm{e}}$ & $61.7^{\mathrm{de}}$ \\
\hline March & 451 & $4.46^{\mathrm{de}}$ & $73.0^{\mathrm{b}}$ & $37.9^{\mathrm{cd}}$ & $3.2^{\mathrm{d}}$ & $62.3^{\mathrm{cd}}$ \\
\hline July & 294 & $4.43^{\mathrm{ef}}$ & $72.1^{\text {cde }}$ & $44.7^{\mathrm{a}}$ & $4.2^{\mathrm{b}}$ & $63.7^{\mathrm{b}}$ \\
\hline August & 329 & $4.41^{\mathrm{ef}}$ & $72.0^{\mathrm{de}}$ & $46.4^{\mathrm{a}}$ & $4.6^{\mathrm{a}}$ & $65.2^{\mathrm{a}}$ \\
\hline September & 476 & $4.63^{\mathrm{b}}$ & $71.9^{\mathrm{e}}$ & $36.6^{\mathrm{de}}$ & $2.8^{\mathrm{e}}$ & $60.5^{\mathrm{e}}$ \\
\hline SEM & & 0.02 & 0.2 & 0.6 & 0.1 & 0.4 \\
\hline$P$-value & & 0.001 & 0.001 & 0.001 & 0.001 & 0.001 \\
\hline
\end{tabular}

${ }^{\mathrm{a}-\mathrm{g}}$ Means in the same column with different superscripts differ $(P \leq 0.05)$ according to Saxton (1998).

${ }^{1}$ Month of sample submittal was assumed to be associated with length of ensiling period.

${ }^{2}$ Number of samples.

${ }^{3}$ Ruminal in vitro starch digestibility at $7 \mathrm{~h}$.

low a pattern and were relatively minor $($ range $=1.6$ percentage units).

Ammonia- $\mathrm{N}$ and soluble $\mathrm{CP}$ concentrations (CP basis) increased $(P=0.001) 155 \%$ and $49 \%$, respectively, from October to August of the following year. Greater soluble- $\mathrm{N}$ concentration was observed when HMC was ensiled up to 90 or $165 \mathrm{~d}$ in the trials of Baron et al. (1986) and Wardynski et al. (1993), respectively. Furthermore, steady increases in ammonia- $\mathrm{N}$ and soluble $\mathrm{CP}$ concentrations over time up to $240 \mathrm{~d}$ of ensiling were observed by Hoffman et al. (2011). From August to September, however, concentrations of ammonia-N and soluble CP were reduced by $39 \%$ and $21 \%$, respectively. This may be related to the submission of samples fermented for a short period or unfermented samples during September.

A 9-percentage-unit increase $(P=0.001)$ in ivStarchD was observed from October to August of the following year. Greater ruminal in situ DM disappearance for HMC was reported previously as the duration of fermentation increased (Benton et al., 2005), and disappearances of DM and starch are highly related in corn grain (Philippeau et al., 1999; Ngonyamo-Majee et al., 2008). In addition, Stock et al. (1991) reported an increased rate of starch digestion as HMC ensiling period length increased from 120 to $365 \mathrm{~d}$. These results are likely related to disruption of the protein matrix crosslinked to starch granules by solubilization or proteolysis during ensiling (Hoffman et al., 2011), thereby allowing for microbial attachment and enzymatic hydrolysis of starch in the rumen (McAllister et al., 1993, 1994). Similar to ammonia-N and soluble $\mathrm{CP}$ concentrations, ivStarchD decreased 4.7 percentage units from August to September which may be related to submission of samples fermented for a short period or unfermented samples during September.

Positive relationships between ivStarchD and ammonia-N $\left(\mathrm{R}^{2}=0.61 ; P=0.001 ;\right.$ Figure $\left.1 \mathrm{~A}\right)$ and soluble $\mathrm{CP}$ $\left(\mathrm{R}^{2}=0.55 ; P=0.001\right.$; Figure $\left.1 \mathrm{~B}\right)$ were observed. Hoffman et al. (2011) reported that lower concentrations of zein-proteins, a well-known inhibitor of microbial fermentation and enzymatic digestion of starch (Kotarski et al., 1992), were associated with greater ammonia-N and soluble CP concentrations after $240 \mathrm{~d}$ of ensiling. Thus, ammonia- $\mathrm{N}$ was suggested in combination with MPS for modeling the effects of corn maturity, DM content, and length of silage fermentation on ruminal and total-tract starch digestibilities and rate of ruminal starch degradation for HMC at feed-out (Hoffman et al., 2012). Results from the present study confirm that ammonia- $\mathrm{N}$ can be a good indicator of starch digestibility for HMC.

Ammonia-N $\left(\mathrm{R}^{2}=0.53 ; P=0.001\right.$; Table 3$)$, soluble $\mathrm{CP}\left(\mathrm{R}^{2}=0.57 ; P=0.001\right.$; Table 3$)$, and ivStarchD $\left(\mathrm{R}^{2}\right.$ $=0.51 ; P=0.001 ;$ Figure $2 \mathrm{~A}$ ) were negatively related to $\mathrm{pH}$. These results are not surprising because the 2 main mechanisms, solubilization and proteolysis, responsible for the disruption of the zein-proteins cross-linked to starch granules occur under acidic conditions. Zeinproteins are soluble in acetic and lactic acids (Lawton, 2002 ), the 2 main fermentation end products of ensiling (Muck, 2010). Furthermore, proteolytic activity, from either microbial or plant proteases, occurs more extensively during the anaerobic fermentation process in HMC (Baron et al., 1986). The anaerobic phase is characterized by a drastic decrease in $\mathrm{pH}$ (Muck, 2010), which favors the activity of plant proteases specific to the endosperm of cereal grains (Simpson, 2001), 

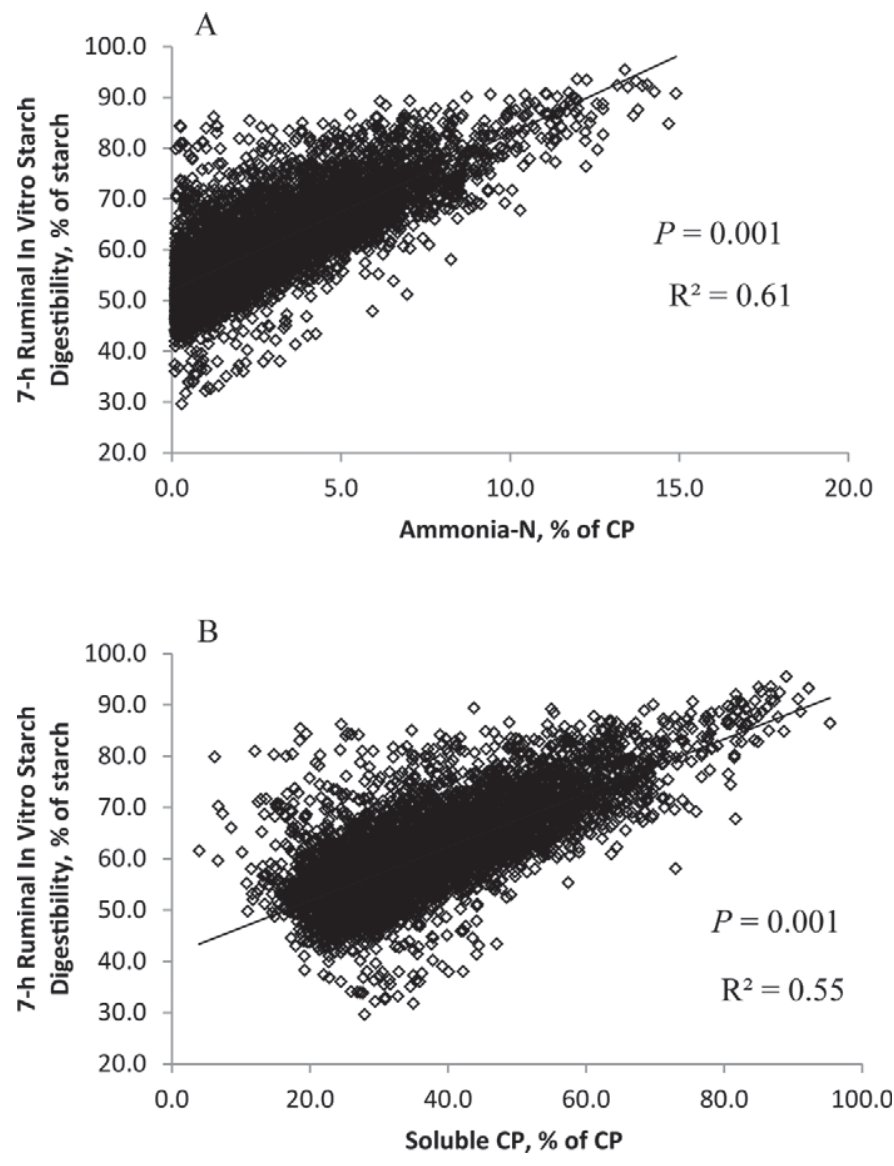

Figure 1. Relationship between ammonia-N or soluble $\mathrm{CP}$ and $7-\mathrm{h}$ ruminal in vitro starch digestibility in high-moisture corn. Ammonia-N (A) prediction equation: $\mathrm{y}=51.98( \pm 0.12)+3.09 \mathrm{x}( \pm 0.03) ; \mathrm{n}=6,131$, root mean square error $(\mathrm{RMSE})=5.94, \mathrm{R}^{2}=0.61, P=0.001$. Soluble $\mathrm{CP}$ (B) prediction equation: $\mathrm{y}=41.34( \pm 0.24)+0.53 \mathrm{x}( \pm 0.01) ; \mathrm{n}=$ $6,131, \mathrm{RMSE}=6.42, \mathrm{R}^{2}=0.55, P=0.001$.

although generally the activity of plant proteases is reduced under low $\mathrm{pH}$ (Muck, 1988). The observed negative relationship between $\mathrm{pH}$ and ammonia- $\mathrm{N}$, soluble $\mathrm{CP}$, or ivStarchD in the present study reinforces the importance of appropriate ensiling practices to reach lower $\mathrm{pH}$ and thereby greater extent of fermentation of HMC.
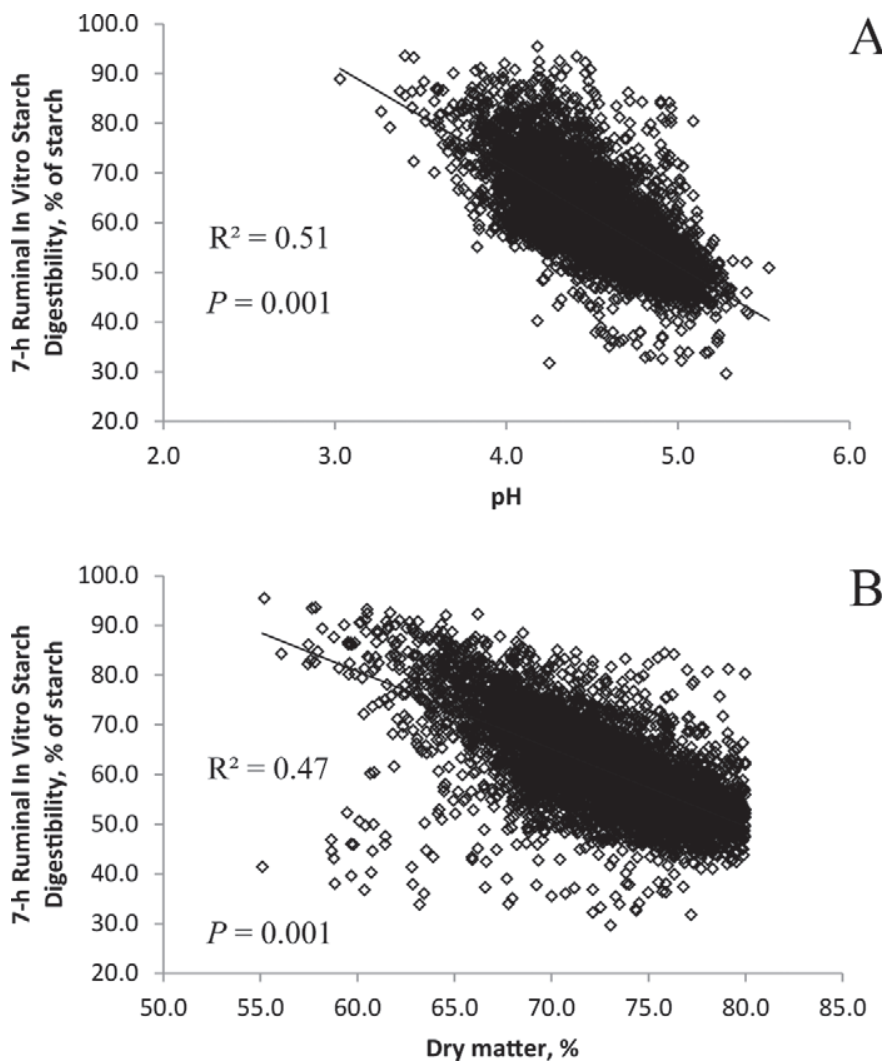

Figure 2. Relationship between $\mathrm{pH}$ or DM content and 7-h ruminal in vitro starch digestibility in high-moisture corn. The $\mathrm{pH}(\mathrm{A})$ prediction equation: $\mathrm{y}=152.20( \pm 1.19)-20.20 \mathrm{x}( \pm 0.26) ; \mathrm{n}=5,927$, root mean square error $(\mathrm{RMSE})=6.70, \mathrm{R}^{2}=0.51, P=0.001$. Dry matter content $(\mathrm{B})$ predictive equation: $\mathrm{y}=174.30( \pm 1.57)-1.56 \mathrm{x}( \pm 0.02)$; $\mathrm{n}=6,131, \mathrm{RMSE}=6.97, \mathrm{R}^{2}=0.47, P=0.001$.

In vitro starch digestibility decreased 1.6 percentage units per 1-percentage-unit increase in DM content of HMC (Figure 2B; $\mathrm{R}^{2}=0.47 ; P=0.001$ ). Although the negative effect of increased DM content or maturity of corn kernels was previously reported in the literature (Correa et al., 2002; Ngonyamo-Majee et al., 2008, 2009), $75 \%$ of the samples in the data set used in the present study had $>70 \% \mathrm{DM}$ and consequently $83 \%$ of the samples were below $70 \%$ ivStarchD (Figure 3). Re-

Table 3. Effect of $\mathrm{pH}$ and $\mathrm{DM}$ content on soluble $\mathrm{CP}$ and ammonia-N in high-moisture corn

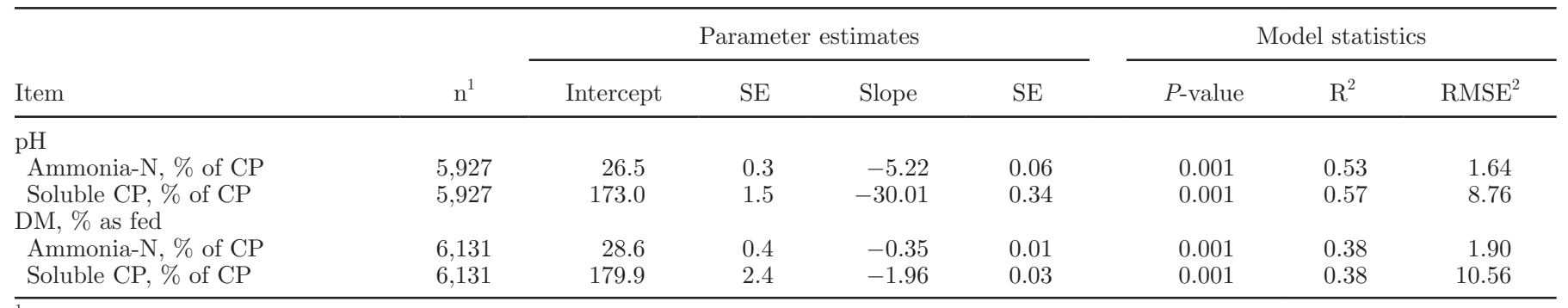

${ }^{1}$ Number of samples.

${ }^{2}$ Root mean square error. 

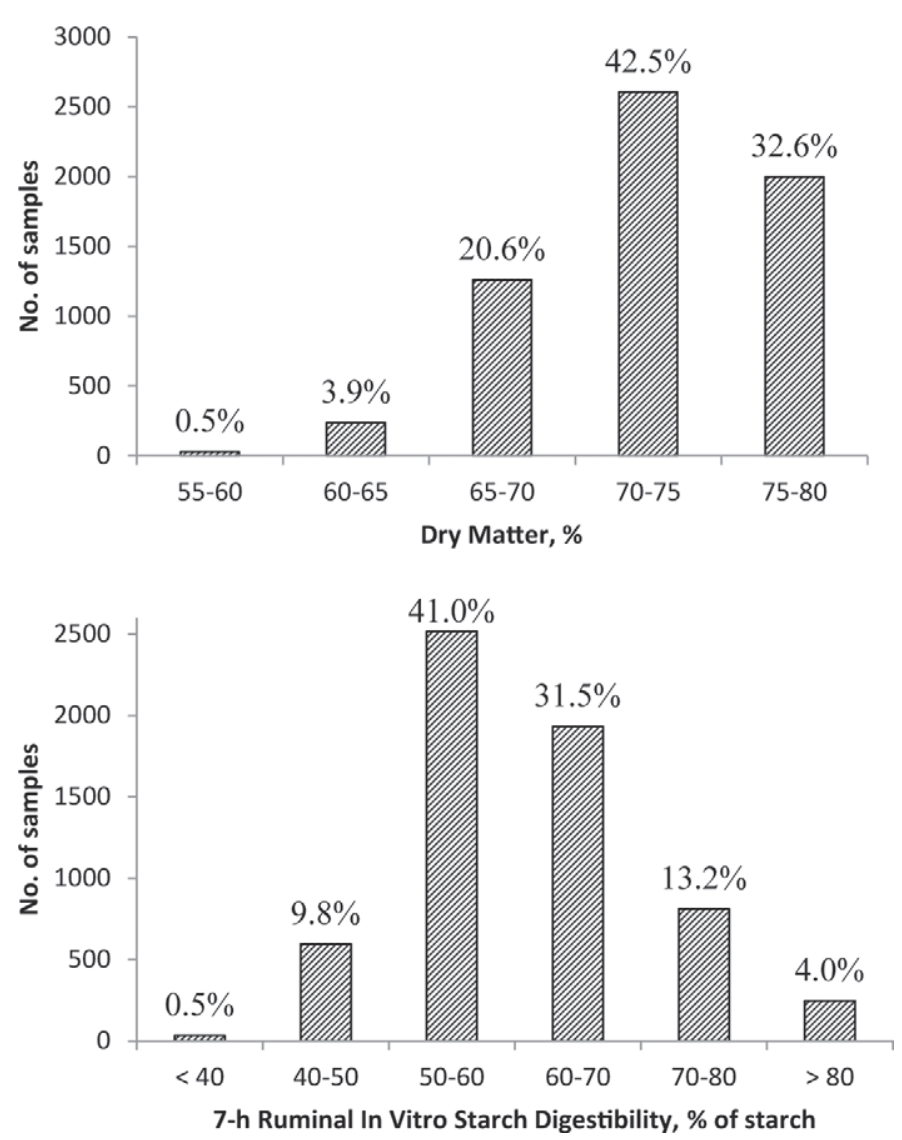

Figure 3. Distribution of samples for DM concentration and 7-h ruminal in vitro starch digestibility.

duced ivStarchD with increasing DM content of HMC could be related either to an increase in the proportion of vitreous endosperm in the kernel associated with greater maturity (Correa et al., 2002; Ngonyamo-Majee et al., 2009) or to a reduction in the extent of fermentation for drier HMC (Table 3, Figure 4). Goodrich et al. (1975) harvested HMC with 67\% DM and oven-dried corn to 73 and $79 \%$ DM to study the effects of moisture content on fermentation of HMC; they observed a decrease in acetate and lactate concentrations and a corresponding increase in $\mathrm{pH}$ as the $\mathrm{DM}$ content of HMC increased. Lower lactate and acetate concentrations are likely related to decreased bacterial growth due to limited water availability (Muck, 1988). Furthermore, Goodrich et al. (1975) observed reduced gas production as DM content increased, suggesting reduced starch digestibility for HMC at greater DM contents. Relationships between DM content and pH (Figure 4), soluble CP (Table 3), or ammonia-N (Table 3) support this theory. In the present study, DM content had a quadratic relationship with $\mathrm{pH}\left(\mathrm{R}^{2}=0.45 ; P=0.001\right)$ with increased $\mathrm{pH}$ as $\mathrm{DM}$ content increased from 65 to $80 \%$. Similar results were observed by others (Baron et al., 1986; Faber et al., 1989) and thought to be related to the decreased concentrations of acetate and lactate as DM content increased. As discussed previously, low $\mathrm{pH}$ and greater concentrations of acetate and lactate are key factors for solubilization or proteolysis of zeinproteins in HMC (Simpson, 2001; Lawton, 2002) and may explain the negative relationship between DM content and ammonia-N $\left(\mathrm{R}^{2}=0.38 ; P=0.001\right)$ or soluble $\mathrm{CP}\left(\mathrm{R}^{2}=0.38 ; P=0.001\right)$ observed in the present study. Greater ammonia-N and soluble-N concentration as DM content decreased were reported previously in the literature (Baron et al., 1986; Faber et al., 1989).

A predictive equation for ivStarchD based on DM content, $\mathrm{pH}$, ammonia- $\mathrm{N}$, and soluble $\mathrm{CP}$ is given in Table 4. A strong relationship was observed (adjusted $\left.\mathrm{R}^{2}=0.70 ; P=0.001\right)$ with $\mathrm{pH}, \mathrm{DM}$ content, ammonia$\mathrm{N}$, and soluble $\mathrm{CP}$, accounting for most of the variation in ivStarchD for HMC. Combining this predictive equation with MPS in an adaptation of the starch digestibility model developed by Hoffman et al. (2012) may provide an alternative to ivStarchD measurements. Further research is warranted to evaluate our predictive equation with other sample data sets for ivStarchD and on combining with MPS in starch digestion models.

\section{CONCLUSIONS}

Ruminal in vitro starch digestibility was greater when HMC was harvested at lower DM content, was ensiled for an extended period, or was lower in $\mathrm{pH}$. These findings highlight the importance of proper harvest maturity and ensiling practices to achieve maximum starch digestibility in HMC. Allowing an extended ensiling period may be beneficial for increasing starch digestibility in situations where coarser, drier, or more vitreous hybrids are harvested, and research

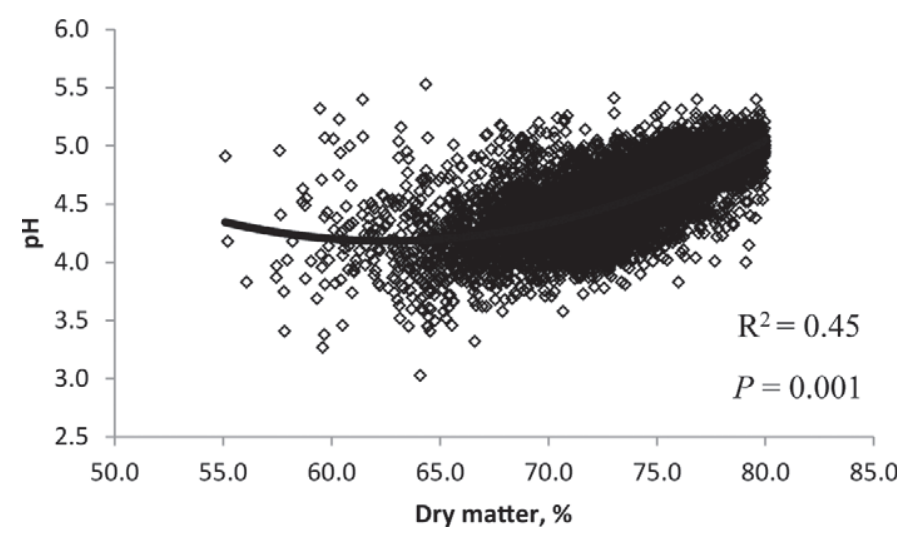

Figure 4. Relationship between DM content and $\mathrm{pH}$ in high-moisture corn. Prediction equation: $\mathrm{y}=15.38( \pm 0.71)-0.36 \mathrm{x}( \pm 0.02)+$ $0.01 \mathrm{x}^{2}( \pm 0.01) ; \mathrm{n}=5,927$, root mean square error $(\mathrm{RMSE})=6.70, \mathrm{R}^{2}$ $=0.45, P=0.001$. 
Philippeau, C., F. Le Deschault de Monredon, and B. Michalet-Doreau. 1999. Relationship between ruminal starch degradation and the physical characteristics of corn grain. J. Anim. Sci. 77:238-243.

Philippeau, C., and B. Michalet-Doreau. 1998. Influence of genotype and ensiling of corn grain on in situ degradation of starch in the rumen. J. Dairy Sci. 81:2178-2184.

Richards, C. J., J. F. Peterson, R. A. Britton, R. A. Stock, and C. R. Krehbiel. 1995. In vitro starch disappearance procedure modifications. Anim. Feed Sci. Technol. 55:35-45.

SAS Institute. 2004. SAS/STAT 9.1 User's Guide. Version 9.1 ed. SAS Institute Inc., Cary, NC.

Saxton, A. M. 1998. A macro for converting mean separation output to letter groupings in Proc Mixed. Pages 1243-1246 in Proc. 23rd SAS Users Group Int., SAS Institute Inc., Cary, NC. SAS Institute Inc., Cary, NC.
Simpson, D. J. 2001. Proteolytic degradation of cereal-prolaminsThe problem with proline. Plant Sci. 161:825-838.

Stock, R. A., M. H. Sindt, R. M. Cleale 4th, and R. A. Britton. 1991. High-moisture corn utilization in finishing cattle. J. Anim. Sci. 69:1645-1656.

Taylor, C. C., and L. Kung Jr. 2002. The effect of Lactobacillus buchneri 40788 on the fermentation and aerobic stability of highmoisture corn in laboratory silos. J. Dairy Sci. 85:1526-1532.

Wardynski, F. A., S. R. Rust, and M. T. Yokoyama. 1993. Effect of microbial inoculation of high-moisture corn on fermentation characteristics, aerobic instability, and cattle performance. J. Anim. Sci. 71:2246-2252. 